\title{
LOS AVATARES DE LOS MUSEOS DE CIENCIA A tRAVÉS DE LOS TIEMPOS: BREVE ESTADO DE LA CUESTIÓN
}

\author{
Francisco Gómez MuÑoz ${ }^{1}$ \\ Silvia InÉs JimÉnez Gómez² \\ Marta Cecilia Palacio Sierra ${ }^{3}$
}

\section{Resumen}

Este artículo corresponde a la investigación La comunicación de la ciencia y la tecnología: Una propuesta para la ciudad de Medellín, del grupo de investigación en Ciencia, Tecnología y Sociedad -CTS- del Instituto Tecnológico Metropolitano, en él se presenta una revisión preliminar acerca de cómo ha sido la comunicación de la ciencia y la tecnología en los museos de CyT, desde la época de los griegos, pasando por el Renacimiento para llegar a la Modernidad y continuar con los museos postmodernos y los del futuro próximo.

En este recorrido se evidencian las transformaciones de los museos de CyT en su búsqueda por ser más eficiente en los pro-

1 Director del Planetario de Medellín, adscrito al Instituto Tecnológico Metropolitano -ITM-. Especialista en Educación. Candidato a doctor en Divulgación de la Ciencia y la Tecnología, Universidad del País Vasco -UPV/EHU-.

Correo electrónico: franciscogomez@itm.edu.co

2 Asesora de Líneas de Investigación del Instituto Tecnológico Metropolitano -ITM-. Magíster en Lingüística y Español, Universidad del Valle. Especialista en la Enseñanza del Español. Universidad Pedagógica Nacional de México.

Correo electrónico: silviajimenez@itm.edu.co

3 Asesora de Líneas de Investigación del Instituto Tecnológico Metropolitano -ITM-. Magíster en Sociología de la Educación. Candidata a doctora en Estudios de Ciencia y Tecnología de la Universidad del País Vasco -UPV/EHU-.

Correo electrónico: martapalacios@itm.edu.co 
cesos de comunicación y, en esa medida, dejar de ser excluyente de la sociedad en general, y ganar espacios que propicien el acercamiento a la ciencia y la tecnología de una manera lúdica, donde la interactividad ocupe un papel importante para su comprensión y para la formación de actitudes y valores que tomen expresión en la opinión y participación ciudadana.

\section{Palabras clave}

Comunicación de la ciencia y la tecnología, Divulgación de la ciencia y la tecnología, Museos, Modernos, Postmodernos y del futuro.

\section{Abstract}

This paper is part of the research project Communicating Science and Technology: A Proposal for the City of Medellin, developed by the Research Group on Science, Technology and Society -CTS- of the Instituto Tecnológico Metropolitano. This project presents a preliminary review of the way communication and science has taken place in science and technology museums from Greek times, through Renaissance, to modern times and also covering postmodern and coming future museums.

This tour shows the transformations undergone by science and technology museums in their search for more efficient communication processes. In the same line, they also try to stop excluding general society and to gain spaces that ludicly benefit a closer relation between science and technology where interactivity plays an important role to understand science and technology and to build attitudes and values that are expressed in the citizens' opinion and participation.

\section{Key words}

Communication of science and technology, Spreading, Museums, Modern museums, Postmodern, Museums of the future. 


\section{INTRODUCCIÓN}

La ciencia hace tiempo que dejó de ser un territorio informativo excluyente, incomprensible y ajeno a la opinión pública. Hablar de la comunicación pública de la ciencia, es hablar sobre la comprensión de la ciencia, es crear opinión pública, brindar una nueva visión de la misma, poner en consideración sus riesgos y, lo más importante, propiciar la participación del ciudadano en asuntos relacionados con las amenazas de alto riesgo, la inequidades asociadas a la apropiación privada del conocimiento científico-tecnológico y el deterioro global medio ambiental (López y Luján, 2002). Comunicar la ciencia y la tecnología es generar en los ciudadanos valores y actitudes de aprecio hacia ellas, pero también posibilitar la comprensión de sus riesgos. En esencia, se trata de contribuir a hacer más democrático el acceso a la ciencia y la tecnología, al mismo tiempo que se vincula a la resolución de las necesidades más sentidas de la inmensa mayoría de personas (Osorio, 2005), lo que implica la creación colectiva y la concepción democrática de su función social. Esto es, hacer partícipe al ciudadano común sobre los resultados e investigaciones que se llevan a cabo y que inciden de manera directa en la cotidianidad de sus vidas. $\mathrm{Y}$ hasta donde sea posible hacerlos partícipes de sus beneficios y aplicaciones.

La comunicación de la ciencia y la tecnología es en la actualidad un área de reflexión que cada vez se fortalece más con las aportaciones de las comunidades de científicos, políticos, educadores y divulgadores, que a partir de la Conferencia Mundial sobre la Ciencia en el Siglo XXI (UNESCO, 1999), han asumido el compromiso de compartir el conocimiento científico y tecnológico mediante la cooperación internacional, haciendo uso de diversas modalidades comunicativas, entre las cuales la educación, los medios de comunicación y los museos juegan un papel preponderante (Núñez, 2003).

La ciencia y la tecnología se han transformado en unos valores estratégicos para la política y la economía (Alonso y Galán, 2004). Esta tendencia, en el mundo globalizado, se incrementa cada vez más, a medida que aumenta el predominio de la denominada socie- 
dad del conocimiento. Es por ello que se hace necesario reflexionar no solamente en cómo funciona la ciencia en una sociedad globalizada, en cómo se produce, sino en cómo se transmite el conocimiento científico y tecnológico y qué retos y problemas nos plantean estos nuevos procesos comunicativos. Pero de antemano, sabemos que se trata de problemas completamente nuevos con respecto a los existentes hace no más de cuarenta o cincuenta años (Quintanilla, 2007), tales como la exclusión de amplios sectores de la población de los avances y logros de la ciencia y la tecnología; la inequidad en cuanto a la apropiación del conocimiento científico-tecnológico entre los países, según sus niveles de desarrollo económico; la carencia de medios y estrategias adecuadas para la divulgación de este tipo de conocimientos en amplios sectores de la sociedad. Así que, en la actualidad, todo país o región debe contemplar entre sus tareas prioritarias la generación de alternativas viables para lograr el propósito de comunicar la ciencia y la tecnología, en función de incrementar su utilidad (Raichvarg y Jacques, 1991).

En Colombia la discusión acerca de la comunicación de la ciencia y la tecnología, es un área de estudio novedosa, abordada desde entidades como el Ministerio de Educación Nacional, Colciencias, las universidades, los museos de ciencia y tecnología $(\mathrm{CyT}) \mathrm{y}$, muy especialmente, por el Convenio Andrés Bello, preocupado por consolidar políticas públicas que posibiliten el fortalecimiento de la actividad científica y tecnológica como una de las estrategias fundamentales para la solución de los problemas sociales.

Actualmente, existen muchos medios por los cuales se trata de comunicar la ciencia y la tecnología: las revistas, los periódicos, los museos, la televisión y ahora fundamentalmente, Internet. Todos ellos enfrentan el complejo problema de cómo divulgar la CyT (Calvo, M. 2003) ${ }^{4}$ y asumen para ello muy diversas formas

4 La divulgación de la ciencia y la tecnología no se reduce a la labor periodística realizada a través de los medios de comunicación (Calvo, MH. 2003), en las propuestas de divulgación hechas desde los museos, confluyen diversos medios de comunicación: periódicos, revistas, programas de televisión, actividades lúdicas y talleres, además en la actualidad los museos comportan su versión virtual. 
y herramientas, bajo las orientaciones de distintos enfoques y modelos, tales como el modelo del déficit y el modelo democrático $\left(\right.$ Lozano, 2005) ${ }^{5}$. Esta diversidad de estrategias conduce a que la mayoría de los medios de comunicación de la ciencia y la tecnología, asuman esta tarea de manera distinta, dando lugar a diferencias marcadas, incluso desde la conceptualización misma, así como de los medios empleados.

Tanto es así, que en los últimos treinta años, los museos se transformaron en el objeto de estudio de más de una disciplina (Podgorny 2005), que pretenden dar respuesta a la complejidad que cobra en la actualidad la comunicación de la ciencia y la tecnología, ya que en ellos es posible observar la confluencia de periódicos, boletines, revistas, programas de radio y televisión, conferencias, eventos y todas las versiones electrónicas de estos medios ${ }^{6}$ acentuando, de esta manera, la necesidad de reflexiones, que más allá de plantearnos interrogantes frente al museo como centro de divulgación del conocimiento, nos conduzcan a indagar acerca de las interrelaciones de los medios que confluyen en él y por ende, apreciar que en la divulgación o popularización de la ciencia y la tecnología que allí se realiza, se encuentran incluidos, también, en su sentido más amplio, todos los modos, maneras y espacios que favorecen una interacción entre la ciencia, la tecnología y el público, dando lugar a que se cree conocimiento, se difunda y hasta se negocie (Ursua, 2004).

Es por ello que este proyecto llevado a cabo por el grupo de investigación CTS del ITM: "La comunicación de la ciencia y la tecnología: una propuesta para la ciudad de Medellín”, pretende indagar acerca de las formas, métodos, estrategias y enfoques que

5 Modelo del déficit: asume la ciencia como motor del progreso o como vía para la solución de problemas. El Modelo Democrático, para el cual la ciencia y la tecnología son fuentes de oportunidades estratégicas. Ver en: Mónica Lozano (2005), Programas y experiencias en popularización de la ciencia y la tecnología, pp. 210-211.

6 Versiones en formatos de CD, DVD y en páginas Web, es decir, en formatos electrónicos, digitales y virtuales. 
orientan los procesos de comunicación en los museos de ciencia y tecnología (CyT).

De esta manera, se nos hace relevante intentar averiguar sobre los antecedentes históricos como base de los actuales planteamientos teóricos, las políticas y las estrategias que orientan las acciones de comunicación de la ciencia y la tecnología en los actuales museos de $\mathrm{CyT}$, no solamente en Colombia, sino de manera general y particularmente, en los museos de la ciudad de Medellín.

\section{Comunicación dE la CIEncia y la tecnología EN LOS MUSEOS DE CYT}

En la mayoría de los museos de CyT, se hace explícito el deseo de llegar a toda clase de públicos, conscientes de la importancia de aportar al desarrollo del país, así como de ayudar a que los ciudadanos comprendan y reconozcan que la ciencia y la tecnología son herramientas fundamentales para mejorar la calidad de vida de la población. Vista así, la labor del museo de CyT se constituye en una práctica sociocultural que promueve el diálogo entre científicos, divulgadores y público en general, con miras a fomentar la comprensión pública de la ciencia y la tecnología, para lo cual es necesario construir una nueva imagen de la comunicación de la ciencia, recuperando los aportes de disciplinas como la sociología, la filosofía y la historia de la ciencia, así como los estudios culturales de ella. Por ello, en esta investigación se asume el término de comunicación de la ciencia y la tecnología, como búsqueda de la participación activa, esto es, la apropiación de la población en la solución de conflictos que involucran el conocimiento científico y tecnológico; o como diría Estrada (2002) lograr la participación en el conocimiento científico a través del diálogo, en el intercambio de saberes y experiencias.

En el mundo de hoy, la ciencia y la tecnología han desarrollado procesos, dinámicas, lenguajes y significados propios que, infortunadamente, marcan una distancia considerable entre la producción del conocimiento y la sociedad en general. Esta situación genera la necesidad de encontrar espacios comunes de diálogo, para trabajar 
por una sociedad cada vez más justa y desarrollada. Lo cual implica que tanto la comunidad científica como las personas involucradas en el ámbito de la comunicación, unan esfuerzos para superar esta distancia, de manera que la ciencia y la tecnología más allá de hacer parte de la vida cotidiana de toda la comunidad genere, a su vez, espacios para una participación democrática en los procesos de apropiación y uso de este conocimiento.

Esta revisión preliminar pretende dar cuenta del interés que se observa actualmente, para que los museos de CyT sean grandes divulgadores de la ciencia y la tecnología.

Es importante tener en cuenta que cuando nos referimos al término comunicación, nos estamos refiriendo a que la comunicación es una práctica sociocultural que promueve el diálogo entre los científicos y el público en general; dicho de otra manera, significa que el público no es solamente receptor sino que desempeña un papel activo en la comprensión pública de la ciencia y la tecnología.

Se trata entonces de que la comunicación de la ciencia y la tecnología como campo de estudio y de investigación se ocupa de las relaciones entre los saberes de los científicos, tecnólogos y expertos, y la sociedad, con sus representaciones sociales y sus propios saberes. (Hermelín, 2007).

\section{UnA Mirada del PASAdO hacia El PRESENTE: COMUNicACIÓN DE CYT, EN LOS MUSEOS}

En los orígenes de los museos se entremezcla, de manera indisoluble, el coleccionismo con la religión, la filosofía, las artes, las matemáticas y la astrología, pero también surgen los primeros intentos de divulgación y de entretenimiento, todo ello en el marco de la sustentación y ostentación del poder.

El desarrollo de las bibliotecas y los museos ha sido el resultado de un proceso histórico complejo, las primeras semillas de los museos están perdidas en las antiguas civilizaciones de la humanidad, de las cuales no persiste información confiable, pero 
gracias a estudios y descubrimientos arqueológicos (Herculano, Pompeya, Egipto, Mesopotamia y Grecia, entre otros) se han develado importantes datos, que pueden configurar antecedentes significativos de los museos y bibliotecas de la modernidad; es el caso de colecciones de objetos ${ }^{7} \mathrm{y}$ de escritos hechos en piedra, cerámica y después en papiro.

Las manifestaciones míticas del coleccionismo tuvieron sus inicios desde las más tempranas épocas, aunque obviamente, no representaban un fenómeno cultural, como se entiende hoy en su dimensión social, pero sí estuvo ligado a los poderes de la sociedad. Son muy conocidos los casos de los templos griegos ${ }^{8}$ y de las tumbas egipcias que debido a creencias religiosas de la época, fueron convertidas en museos en los que se acumulaban grabados, inscripciones, objetos, figuras y animales, entre los objetos que debían ayudar al finado, de acuerdo con su clase social, a soportar la vida de ultratumba.

Es posible reconocer entonces, en esta antigua tradición del coleccionismo, los elementos básicos para comprender la dificultad que presentan algunos museos para renovar su concepción frente a lo que debe ser un museo contemporáneo de CyT, ya que si bien, la presencia de los objetos permiten acercar la ciencia y la tecnología a los ciudadanos, desde una visión contemporánea se trata más bien de buscar un acercamiento de la sociedad a los conceptos de la ciencia, promoviendo la participación pública en los procesos de producción del conocimiento y la apropiación democrática de la ciencia y la tecnología (Osorio, 2007).

7 Se sabe que Tutmosis III (1504-1450 a. de C.) formó una colección de ejemplares de flora y fauna de Asia conseguida en sus campañas y que Amenofis III (1417-1379 a. de C.) fue coleccionista, sobre todo, de esmaltes azules. G. LEWIS: "Museums and their precursors: a brief world survey", J THOMPSON (ed.): Manual of Curatorship. A guide to museum practice, Londres-Boston, Butterworth's, 1992, 2a ed., p. 5.

8 Las colecciones griegas no se alojaban en los museos, nombre dedicado en ese entonces a las escuelas filosóficas, pero sí en los templos y, en ocasiones, en edificios levantados para tal fin, donde se reunían obras de arte, armas y trofeos que adquirían el carácter de reliquias y curiosidades de la naturaleza (animales exóticos embalsamados, piedras raras...). (VALDÉS, 1999, p. 29) 


\subsection{Museos ancestrales}

La idea de museo se concibió y modeló en el Liceo de Aristóteles, en Atenas, y fue después llevada a la práctica por un seguidor suyo, Demetrius, quien sería el primer director del Museion. En el Museion confluyeron religión, filosofía, arte, ciencia y educación, pero ante todo se constituyó en un instrumento político para respaldar el poder de los griegos, particularmente el del general Ptolomeo Soter, quien a la muerte de Alejandro, asumió el poder en Egipto e instauró la dinastía de los Ptolomeos (o dinastía Lágida) que gobernaría a Egipto hasta Cleopatra (Cleopatra Filopator Nea Thea, Cleopatra VII), última reina de esa estirpe (vivió entre el año 69 y el año 30 a.C.).

El Museion ${ }^{9}$, templo en honor a las musas, de él hacía parte la biblioteca de Alejandría y se referencia como el primer museo del cual se tengan noticias fiables, la primera mención de la que se tiene noticia está registrada en "La Carta de Aristeas" (180-145 a.C), su construcción fue iniciada alrededor del año 300 $\mathrm{aC}$, por un general al servicio de Alejandro Magno, Ptolomeo I Soter (Salvador), quien se constituyera en el primer faraón de la era helenística de los Ptolomeos, luego el Museion fue terminado por su hijo Ptolomeo II Philadelphus, en el año 283 a.C. A su construcción le siguió una turbulenta historia, que se hace difícil reconstruir cronológicamente, debido a la multiplicidad de fuentes e intereses culturales de quienes la reconstruyen.

9 Museion casa de las nueve musas, que representan el ideal griego, interrelación entre las artes y las ciencias, hijas de Mnemosyne y por esta razón, también llamado, la casa de las hijas de la memoria. Museion es el origen de los vocablos ingleses museum y amusement. J P Russo: Future Without a Past: The Humanities in a Technological Society, Editorial: University of Missouri Press: 2005, P. 62. 
Del Museion ${ }^{10}$, se dice, disponía de habitaciones y restaurante, claustros y salas de conferencias, laboratorios, observatorios astronómicos, jardines para las discusiones filosóficas (peripatéticas), zoológico y la propia biblioteca de Alejandría. También albergaba y se usaban para la enseñanza, objetos como instrumentos quirúrgicos y astronómicos, pieles de animales, colmillos de elefantes y bustos. Se dice que el faraón sostenía el Museion y al grupo de sabios que habitaba en él, además era visitado con frecuencia por cientos de niños que habitaban la ciudad. Cabe recordar que Alejandría era una ciudad cosmopolita, enlace entre varias culturas, la egipcia, la judía, la romana y la griega. Sin embargo, al interior del Museion sólo podía acceder un pequeño grupo de privilegiados, de una sociedad que les permitía vivir para pensar, crear y transmitir conocimientos, ellos dedicaron parte de su tiempo a la realización de estudios sistemáticos de literatura griega, a editar, criticar y coleccionar los clásicos griegos, a realizar traducciones del griego a otros idiomas como el asirio, persa, hebreo e indio.

Es posible encontrar actualmente en los museos de CyT y "casas de la ciencia”, una búsqueda para hacer de estos espacios, un lugar donde confluyan múltiples acciones de carácter científico tecnológico, nucleadas por una propuesta educativa que posibilite el acercamiento de la comunidad a la ciencia y la tecnología.

Entonces, asumir el museo de $\mathrm{CyT}$ como un objeto de estudio, implica dar cuenta de manera analítica de sus componentes e interacciones y en ese sentido, se hace necesario indagar la labor que allí han desempeñado las bibliotecas. De ellas, la imagen que perdura y ha llegado hasta nuestros días, un buen ejemplo, es la biblioteca de Alejandría donde el poeta Calímaco, que murió en el año 240 de nuestra era, realizó el mayor catálogo de rollos papiros con más de 700.000 obras, escritas por prominentes filósofos, poetas y científicos naturales, entre otros.

10 Frederick Lerner comenta: Como el faro de Alejandría significaba la maestría sobre la noche y la distancia, "el Museion" incorporó al hombre la capacidad de superar los límites del tiempo. Lerner afirma que Alejandría "representa la habilidad del hombre para trascender las nubes del tiempo". 
La confluencia de las ciencias en dichos espacios, como otro de estos componentes fundamentales, se logró a través de los textos escritos, pero también con las actividades de científicos y filósofos. La medicina y la astronomía ${ }^{11}$, entre ellas, son los brazos más antiguos de las ciencias naturales y se relacionaron de diversas formas con las actividades del museo. Las matemáticas y la filosofía tuvieron una relación muy creativa y se influenciaron mutuamente, para evocar esos fructíferos intercambios, entre la filosofía y las matemáticas, basta recordar las actividades de los pitagóricos y a Zenón, con su método deductivo axiomático. La medicina primitiva, la filosofía y la astronomía son buenos ejemplos de la interrelación entre ciencias especulativas y las formas empíricas del pensar de la época, que estuvieron presentes en los más antiguos museos.

El lado oscuro del Museion ${ }^{12}$, escriben algunos autores, es el ser un espacio para elegidos, en el que los conocimientos más importantes permanecieron en el pequeño círculo de privilegiados, fuera de sus límites sólo salieron desarrollos para entretener a los nobles y poderosos, pocas aplicaciones prácticas (excepto para la guerra), se estimuló la superstición, el público no tenía idea de los descubrimientos y, por supuesto, los esclavos no podían acceder al Museion, pues para la época no eran considerados seres humanos. De estas tradiciones derivamos valiosos elementos que son útiles para confrontar las actuales prácticas museísticas, ya que si bien en la actualidad no existen los rasgos fundamentales de la organización social esclavista que predominó en esta época, siguen vigentes las actuales divisiones en la estructura social y, por ello, es posible reconocer que, dado el creciente proceso de privatización del

11 La astronomía en sus inicios se confundía con la astrología (arte de la adivinación del futuro), pero la observación cuidadosa del cielo condujo a la humanidad a las medidas más precisas del tiempo y del cambio climático, en particular, a un paulatino acercamiento a la astronomía y la cosmología como ciencias.

12 En el Museion todavía estaba ausente la valoración de los objetos como testimonios del pasado histórico, el aprecio de una obra por su creador y el mercado de antigüedades. VALDÉS SAGÜES: "La difusión cultural en el museo: servicios destinados al gran público”. Gijón, España, Trea, 1999, p. 29. 
conocimiento científico-tecnológico, cada vez más, amplios sectores de la sociedad son excluidos de sus logros y avances.

Como expresión social, las distintas vertientes de las ideologías políticas, religiosas, éticas y estéticas hacen presencia en la constitución del museo, tendencias que es posible rastrear claramente en el templo hermano al Museion, el Serapeion, erigido en honor al Dios Serapis, un dios inventado por los Ptolomeos como una síntesis de Zeus, Plutón, Osiris y Apis, ubicado en el sector egipcio de la ciudad, lejos del Museion y abierto a todos los públicos (excepto a los esclavos, por las razones antes dichas).

En resumen, el Museion griego era un espacio en el que vivían los elegidos del faraón; con frecuencia el museo era visitado por los niños, pero no por todos los niños, solamente accedían los hijos de las clases privilegiadas. Aun cuando se generó ciencia, filosofía, literatura y cultura en general, ella no trascendió los muros del Museion, sus inventos prácticos estuvieron al servicio de la guerra, o al entretenimiento de los nobles y poderosos. Se sembró allí el germen de la divulgación del conocimiento y se empezó a gestar una especie de contrato social con la ciencia, pero finalmente sucumbió a los intereses políticos y económicos de las diversas culturas dominantes. En segundo término, y paradójicamente, fue un centro para preservar la cultura occidental ancestral y simultáneamente fue un instrumento de imposición y preservación del poder helenístico de los faraones. Por último, es notable su intención de educar y divertir, para mantener el statu quo y preservar el imperio, de lo cual surgen preguntas que es necesario responder de manera crítica frente al rol social que cumplen en la actualidad muchos museos de CyT y que nos llevan a indagar si es ésta, todavía, una condición de existencia del museo de la postmodernidad o en otras palabras ¿es el museo un espacio conservador de las condiciones prevalecientes en la sociedad?, ¿es un instrumento de poder del Estado?, ¿qué se puede esperar del museo de $\mathrm{Cy} T$ en materia de participación ciudadana en la ciencia y la tecnología?, ¿se incluye en la agenda de los museos la alfabetización científica tecnológica del público? 
Afirma Ursua (2004), al referirse a las ciencias, que éstas "han sido consideradas en el pasado como una especie de cultura $<$ privada>, o al menos esotérica, separada de la experiencia, de la competencia y de la comprensión del público, incluso de los miembros de la elite educada de manera general".

\subsection{Museo Renacentista}

En la época del Renacimiento, entre los siglos XV y XVIII, se propició en Europa un coleccionismo desmesurado y variado que ha requerido de muchos años para ser analizado y ordenado, éste es el producto de las exploraciones geográficas, las investigaciones naturales, los grandes avances científicos, los estudios antropológicos, los intercambios económicos y culturales y las guerras entre pueblos de diversas latitudes.

Los gabinetes de curiosidades ${ }^{13}$ o cuartos de maravillas, las colecciones y las galerías privadas del Renacimiento, generalmente tenían la pretensión de resaltar el poder del propietario y su familia, y de satisfacer la curiosidad de aristócratas, negociantes, intelectuales, científicos y especialistas o simplemente amigos de los propietarios, eran visitados ocasionalmente por grupos muy selectos de personas. Estos gabinetes permiten inferir cómo estaban ubicados socialmente: el científico, el artista y el coleccionador. El museo del Vaticano ${ }^{14}$, por ejemplo, era visitado únicamente una vez al año, los viernes santos.

13 Los Cuartos de Maravillas o Gabinetes de Curiosidades designan los lugares en los que durante la época de las grandes exploraciones y descubrimientos, siglo XVI y siglo XVII, se coleccionaban y se presentaban una multitud de objetos raros o extraños que representan todos o alguno de los tres reinos considerados en la época; animalia, vegetalia y mineralia; además de realizaciones humanas.

14 Julius von Schlosser señala que "el concepto de cámara artística y maravillosa no ha existido propiamente en Italia con la precisión que en el norte Alemán", ya que en aquel país los valores artísticos, junto con los puramente científicos e históricos, primaron desde las colecciones más antiguas. Lo curioso es que los objetos raros ocuparon sólo un lugar secundario. Las cámaras artísticas y maravillosas del renacimiento tardío. Una contribución a la historia del coleccionismo, Madrid, Akal, 1988, p. 41. 
Los gabinetes de curiosidades, como su nombre lo indica, contenían objetos meramente curiosos o francamente asombrosos, en su mayoría sirvieron como tema de conversación para unos pocos nobles o comerciantes; algunos gabinetes se conservan actualmente y se constituyen en los museos de ciencia de primera generación ${ }^{15}$, precursores del actual museo de ciencia. Prototipos de esta generación de museos son los Museos de Historia de Florencia ${ }^{16} \mathrm{y}$ Londres ${ }^{17}$. La cualidad dominante de los gabinetes de curiosidades es la reunión de variadísimos productos, de pequeños a grandes, de estéticos a funcionales, de comunes a exóticos.

El proceso de transformación de entidades privadas en institucionales y públicas, permitió una primera clasificación en colecciones de productos naturales (naturalia) y humanos (artificialia), los cuales se convirtieron en el núcleo primario de los museos laicos. Este proceso se realizó durante un largo período comprendido entre los siglos XVIII y XIX, entre las posibles causas se pueden considerar: la socialización de los bienes reales como consecuencia de la revolución francesa y por la influencia de los enciclopedistas, la exclaustración de religiosos y la venta de sus bienes, promovidas por legislaciones y muchas otras razones de orden filosófico, científico e histórico.

En 1661, la Universidad de Basilea instauró el primer museo universitario en Europa, ejemplo secundado años más tarde por la Universidad de Oxford al abrir el célebre Ashmolean Museum ${ }^{18}$ en marzo de 1683, considerado el primer museo público de carácter pedagógico $^{19}$.

15 Museos de primera generación: son los tradicionales de ciencias y de arte. Se pone énfasis en la herencia cultural a través de la conservación y exposición de objetos, seleccionados por su alto valor intrínseco. Su enfoque es meramente expositivo. Se preocupan por estimular la participación creativa del visitante, aunque el papel de éste es pasivo. (Lozano, 2005)

16 http://galileo.imss.firenze.it/

$17 \mathrm{http}: / /$ www.nhm.ac.uk/

18 http://www.ashmol.ox.ac.uk/

19 Opinión del renombrado museólogo francés Germain Bazin (1969). 
Un museo típico de esta época es el Museo Británico ${ }^{20}$, de la Inglaterra victoriana, en el que eruditos y científicos que desarrollaron el gusto por la exploración, la observación de la naturaleza, los viajes de exploración y el coleccionismo, conformaban clubes, sociedades científicas y todo tipo de asociaciones; sin embargo, eran asociaciones cerradas, el público podía acceder a los espacios del museo en horarios especiales y guardando estrictas medidas de comportamiento, las actividades de divulgación se circunscribían a escuchar el discurso del guía sin muchas posibilidades de interactuar con él.

Museos, todos, en los que es prohibido tocar (ver y no tocar), centrados en el objeto y la colección, el visitante además de pertenecer a un círculo social determinado, era un visitante pasivo del museo, su característica fundamental era y es la de conservar objetos preciosos y raros, obras de la naturaleza y del hombre, no obstante, representan con mayor propiedad la concepción clásica del museo como almacén. A pesar de lo anterior, las colecciones del Renacimiento se pueden considerar como un antecedente importante del museo moderno y son consideradas como los museos de ciencia de primera generación ${ }^{21}$.

Para concluir, en los gabinetes de curiosidades subyacen igual que en los anteriores la diversión, ostentación del poder y el coleccionismo, ha desaparecido, o no es muy significativa, una función importante del Museion griego, la intención de educar, que es retomada por algunos museos universitarios. Sin embargo, en estos museos se realizaron algunas actividades científicas importantes en lo relacionado con la clasificación de los objetos, actividad que evolucionaría, posteriormente, a las clasificaciones científicas de los vegetales (botánica), la clasificación de animales y de los minerales. Otra intencionalidad de los museos fue la de

http://www.thebritishmuseum.ac.uk/

21 Según clasificación de los museos científico-tecnológicos propuesta por el Dr. Antonio E. Ten, Universidad de Valencia - CSIC, en LOS MUSEOS CIENTÍFICOTECNOLÓGICOS. Un ensayo de clasificación por generaciones: http://www.uv.es/ ten/ p64.html 
coleccionar con el ánimo de salvar y abrir ventanas al pasado, se trataba de encontrar el orden de la creación divina, de esta manera se conservaron varias de la características del Museion griego, todavía no se presentaba una separación clara entre ciencia, arte y religión, y eran instituciones para públicos muy selectos.

\section{Del gabinete de curiosidades al muSeo moderno DE CIENCIA Y TECNOLOGÍA}

\subsection{Impacto de la revolución científica}

El concepto de museo en la modernidad está asociado a la revolución científica y a las transformaciones de la sociedad medieval a la sociedad moderna lo que corresponde a un largo periodo que se inicia en el siglo XVI, con las obras de Nicolás Copérnico, posteriormente, con Galileo; la Física adquiere el estatus de ciencia, mediante la concepción de un modelo que deberían seguir las disciplinas que quisieran adquirir la categoría de ciencias, en términos muy generales, se trata de tener un control racional de la experiencia y mostrar cómo es posible matematizar los fenómenos naturales, buscar leyes generales, estudiar fenómenos y no realidades, dejando al experimento la prueba crucial que determina el carácter científico de las teorías, se gesta de esta manera el cambio que conduciría al paso del museo centrado en el objeto al museo centrado en el público. El éxito de la revolución científica radica en su capacidad para combinar las funciones del erudito, su razonamiento lógico matemático, con la técnica del artesano para construir objetos. Es allí donde podemos encontrar en la actualidad otros de los componentes básicos que nos ayuden a comprender lo que hoy es el museo de CyT.

$\mathrm{Al}$ lado de la revolución científica, la deconstrucción ${ }^{22}$ del teocentrismo medieval y la aparición paulatina del naturalismo

22 Derrida explica que empleó el término «deconstrucción», término poco usual en francés, para retomar en cierto modo, dentro de su pensamiento, las nociones heideggerianas de la "Destruktiom» de la historia de la ontoteología (que hay que entender no ya como mera destrucción, sino como «desestructuración para 
como paradigma dominante, la conciencia de que Dios no se podría constituir más en el único marco explicativo, abrió caminos al sujeto del conocimiento para asumir nuevas posturas y buscar explicaciones alternativas. La revolución científica inaugurada con la explicación del heliocentrismo, corresponde a un cuestionamiento de la posición central del hombre y del planeta, y los estudios posteriores de Charles Darwin en el siglo XVII, generan un malestar y tensión con las explicaciones establecidas y con la filosofía escolástica, igualmente, establece diferencias entre el arte y la ciencia ${ }^{23}$, se diferencian las actividades del artista y del científico, las clasificaciones hacen que dos actividades humanas tomen caminos diversos y se empieza a gestar el individualismo moderno.

Adicionalmente, la revolución científica puso en evidencia la necesidad de un contrato social, que posibilitara el apoyo del Estado a la ciencia, de hecho, Galileo ofreció clases de Astronomía a los Médicis y sus publicaciones en lenguas vernáculas buscaban llegar a un público más amplio, a pesar de ello, se consideraba que la ciencia solo podía ser abordada por los entendidos y era escrita para ellos.

La revolución científica evidenciará su influencia sobre los museos de ciencia y tecnología posteriormente, particularmente después de la revolución francesa y de la revolución tecnológica del siglo XVIII, cuando se configuran los museos de ciencia de la modernidad; el museo evidenció así su carácter conservador, sin embargo, fue el lugar donde se conformaron las sociedades científicas y se alcanzaron logros importantes en la clasificación de los animales, los vegetales y los minerales, dando lugar a una tipología

destacar algunas etapas estructurales dentro del sistema») y de la "Abbau" (operación consistente en «deshacer una edificación para ver cómo está constituida o desconstituida»).

23 En el año 1794, Fiedrich Schiller concibió el proyecto de compensar la abstracción del saber moderno con el saber poético, en su revista Die Horen, en ese proyecto de unir la descripción científica de la naturaleza y su descripción literaria fue apoyado por Alexander Von Humboldt. 
de museo en el que se mantienen las prácticas determinadas por la necesidad intrínseca de exhibir objetos de carácter novedoso que capten la atención del público y en este sentido, los objetos de las nuevas tecnologías se transforman en una más de las atracciones. Lo cual nos conduce a generar nuevamente cuestionamientos acerca de la forma como se operan las transformaciones en las prácticas museísticas, donde si bien las renovaciones ocurren en cuanto a qué se exhibe, pero no son visibles transformaciones significativas en cuanto al cómo, el para qué y él para quién se exhiben.

\subsection{Impacto de la revolución francesa y de la revolución industrial en el museo de CyT}

Después de la revolución francesa se consolida el tránsito de los museos del ámbito privado al ámbito público, este tránsito se acelera con la revolución industrial. Las condiciones sociales, económicas y políticas de la época no sólo favorecen, sino que exigen el acceso a la cultura y a la educación de grandes masas de la población, de esta forma los museos pasan a formar parte de la vida cotidiana de los ciudadanos (Rivière, 1993).

Como se mencionó anteriormente, es a partir de mediados del siglo XVIII, desde la revolución francesa y por influencia de los enciclopedistas, cuando los museos dejan de ser patrimonios privados y empiezan a tener una nueva connotación. El museo, particularmente el de ciencia, tiene nuevas intencionalidades, entre ellas la de enseñar ${ }^{24}$, un ejemplo clásico es el Conservatoire National des Arts et Métiers ${ }^{25}$ con su anexo, el Musée des Techniques (Bonnefous, 1987), en Versalles, cuyo origen se encuentra en el decreto de la Convención del diez de octubre de 1794. La función principal de este conservatorio era el de ser un depósito público de máquinas, herramientas, modelos, diseños, descripciones y libros de todos los

24 En el siglo XVII aparecen las primeras publicaciones de carácter divulgativo, un ejemplo de ellas son las primeras publicaciones de carácter científico - Journal de Sçavants, Paris, 1935.

$25 \mathrm{http} / / / \mathrm{www} . c n a m-$ versailles.fr/ 
géneros de artes y oficios. En el museo se buscaba enseñar (educar formalmente ${ }^{26}$ ) a los nuevos técnicos en el funcionamiento de dichas máquinas y herramientas; por primera vez en sesiones públicas se mostraban las máquinas en funcionamiento y se acercaba al público a la técnica y a la ciencia de la época, se evolucionó del gabinete de curiosidades al museo tecnológico por excelencia.

Para la época se hacía urgente la formación de personas capaces de operar y reparar las nuevas máquinas que aparecen a partir del descubrimiento de la máquina de vapor ${ }^{27}$, reaparece con gran fuerza la vocación educadora del museo, que ya se vislumbraba en el Ashmolean Museum y mucho antes en el Museion Alejandrino, surge desde entonces el debate entre los diversos tipos de formación que debe ofrecer el museo: formal, no formal o informal, y el para qué de esa formación; en todos los casos el museo adopta una marcada tendencia didáctica y pedagógica, bajo la influencia de fuertes presiones políticas y económicas. Igualmente el público cambia su rol pasivo a uno más activo, que involucra su interacción con los objetos exhibidos y nuevos aprendizajes, empieza a gestarse el cambio de la interacción simple con los objeto a una interacción compleja con los objetos y a través de éstos con las ideas.

\section{MuSEO MOdERno dE CIENCIA Y TECNOLOGía}

Con el cambio de vocación del museo se fue generando simultáneamente interés por mostrar las implicaciones sociales, económicas, políticas, éticas y estéticas de la tecnología y el avance de la ciencia, acompañado dicho interés por reflexiones filosóficas que se adentraron en el cuestionamiento de las prácticas de producción del conocimiento científico-tecnológico y de sus impactos en la sociedad.

26 El museo otorga certificados de competencia laboral.

27 La máquina de vapor independiza al hombre de otras fuentes de energía, que algunas veces dependían de la ubicación geográfica (energía eólica e hídrica) o de la energía suministrada por hombres y animales, condición que favorece la producción industrial. 
En ese período se realizaron múltiples exhibiciones temporales de temas científicos e industriales, regionales, nacionales o universales (Gibbs, 1981) en diversas partes del mundo, justamente en la exhibición mundial ${ }^{28}$ de las aplicaciones industriales de las artes y las ciencias, en 1851, en Gran Bretaña, se genera la necesidad de crear un museo $^{29}$; es así como en 1857 nace el Science Museum ${ }^{30}$ con el objetivo de exhibir los inventos, máquinas e instrumentos que estaban almacenados en el antiguo Museo de las Patentes, así como las que surgieran en un futuro ${ }^{31}$. Con el Science Museum Británico se abrió paso el concepto actual del museo de ciencias, como un espacio en el que se acerca al público a los principios y leyes científicas y a los nuevos desarrollos de la tecnología, mediante la educación informal.

Un museo notable, que retomó la senda de la educación formal, fue el Deutsches Museum de Alemania ${ }^{32}$ (1906), convirtiéndose en un espacio del pensamiento científico y tecnológico nacional. Tras sobrevivir a la segunda guerra mundial, y luego de su reconstrucción, el Deutsches Museum inicia una nueva etapa en la que incluye contribuciones científicas y tecnológicas de otros pueblos.

La nueva pregunta que surge de este contexto es ¿El ideal de progreso debería estar centrado en la industria, la ciencia y la tecnología? Las nuevas y profundas desigualdades sociales que genera la revolución industrial, ponen en duda ese ideal de

28 "Las exposiciones universales inspiraron la creación de numerosos e importantes museos, sobre todo de aquellos dedicados a la ciencia y la tecnología”, afirma Robert Brain.

$29 \quad$ El South Kensington Museum de Londres, el Technische Museum für Industrie und Gewerbe de Viena, el Deutsches Museum de Munich y el Museum of Science and Industry de Chicago se fundaron tras el éxito de las exposiciones de Londres (1851), Viena (1873), París (1881) y Chicago.

30 http://www.sciencemuseum.org.uk/

31 "No eran lo que nosotros consideraríamos museos de ciencia o el equivalente de los modernos science centres. Eran en realidad bibliotecas de aparatos". Butler, S. V. F.: Science and Technology Museums, Leicester-Londres-Nueva York, Leicester University Press, 1992.

32 http://www.deutsches-museum.de/ 
progreso. En estas condiciones se genera, entonces, otra pregunta ¿Cuál es el papel de los museos de CyT?

Los museos de la época se generaron con el propósito de proporcionar educación para todas las clases sociales, no obstante, los intereses económicos de la nueva sociedad entregada al capitalismo, fueron cruciales en la conformación del contexto que dio origen al museo moderno. De alguna manera el ideal de progreso, mostrado en el museo, de una ciencia y tecnología que proporciona soluciones a los problemas del ser humano, fue perdiendo credibilidad por las consecuencias que ofrecía el desarrollo industrial.

Los museos tecnológicos que se fueron consolidando en Europa y América, corresponden a la segunda generación ${ }^{33}$ de museos científico-tecnológicos, nacidos de la revolución industrial y con una vocación claramente pedagógica dirigida a las clases artesanas, aunque no se consolidaron como centros de enseñanza formal, se convirtieron en su complemento e introdujeron métodos revolucionarios de enseñanza "a través de la observación y la experimentación"; ampliaron la función del museo de ciencia a la promoción de métodos didácticos de enseñanza, como apoyo a la academia, así como capacitación para docentes y público en general sobre temas específicos de ciencia y tecnología, son ellos los museos de principios del siglo XX. En éstos el paradigma de divulgación se centra en ilustrar al que no sabe, hay comunicación unidireccional de la ciencia y la tecnología y todavía, en ellos, se evidencia el culto al objeto ${ }^{34}$, aunque se empieza a interactuar con los objetos y las ideas, este no es el rol más significativo de museo de CyT.

33 Museos de segunda generación: son los primeros museos de CyT. Muestran la historia de la ciencia y promueven la tecnología nacional. Aparece por primera vez la necesidad de vincular activamente a los visitantes. Su enfoque es demostrativo, esto es, cómo funcionan las cosas a partir de exhibiciones que reaccionan a la puesta en marcha por parte del visitante. El papel de éste (visitante) es receptivo. (Lozano, 2005)

34 Antes del surgimiento de los museos tecnológicos, se presenta un marcado interés, de los museos por la arqueología y la recuperación y clasificación de los testimonios históricos de la humanidad. El museo se veía como un instrumento para conservar las reliquias del pasado. 


\subsection{Museo interactivo de ciencia del siglo XX}

Un nuevo concepto de divulgación se abre paso a mediados del siglo XX, se trata de los museos conocidos como Science Centers en los países anglosajones, museos de tercera generación ${ }^{35}$; en ellos se privilegia la experiencia sobre el objeto; se desarrolla el concepto de "hands on science", que implica involucrar al visitante como centro del proceso interactivo en la divulgación de la ciencia; éste se envuelve en el experimento, se hace parte de él, plantea sus propias preguntas (o son planteadas por el museo); se sugieren algunas posibles respuestas y es el visitante quien extrae sus propias conclusiones. Otra pretensión del museo es educar sorprendiendo y deleitando, aprendizaje con gozo y nueva creación de aprendizaje para la popularización y divulgación de la ciencia y la tecnología, mediante la educación informal.

Uno de los casos más notables de esta generación de museos es el Exploratorium ${ }^{36}$ de San Francisco (1969), su fundador y primer director fue el Frank Oppenheimer, científico y divulgador, quien lo fundó como "museo de la ciencia, el arte y la percepción humana". Es importante resaltar otros museos de esta generación que resaltan el ingenio y creatividad de la humanidad:

- Palais de la Décuverte de Paris ${ }^{37}$ (1937)

- Museo Nacional de La Ciencia de Tokio ${ }^{38}$ (1931)

- Ontario Science Center de Toronto ${ }^{39}$ (1969)

- Museu de Ciències Naturals de Barcelona ${ }^{40}$ (1981)

${ }^{35}$ Museos de tercera generación: corresponden los centros interactivos de ciencia. Estos centros son colecciones de ideas, de fenómenos naturales y de principios científicos, más que de objetos. Se da la participación activa del visitante; su enfoque es interactivo. (Lozano, 2005)

$36 \mathrm{http}: / /$ www.exploratorium.edu/

37 http://www.palais-decouverte.fr/

38 http://www.jsf.or.jp/index_e.html

$39 \mathrm{http}: / /$ www.ontariosciencecentre.ca/

40 http://bcnweb13.bcn.es:81/NASApp/wprmuseuciencies/Museu.GeneradorPagines 
- La Cité des Sciences et de l'Idustrie de la Villete ${ }^{41}$ (1986)

- Casa de la Ciencia y el Centro de Ciencias del estado de Río de Janeiro ${ }^{42}$ (1987)

- Universum de México ${ }^{43}$ (1992)

- Museo de la Ciencia y el Juego ${ }^{44}$ de Bogotá

- Kutxaespacio de San Sebastián ${ }^{45}$

- Maloka ${ }^{46}$ de Bogotá (1998)

Las características más relevantes de estos museos consisten en explicar la ciencia contemporánea, sus alcances y limitaciones, los riesgos que encierran los desarrollos científicos y tecnológicos y los horizontes que abren los nuevos descubrimientos, la motivación a los visitantes a participar activamente en las exhibiciones y en lo posible a razonar autónomamente sobre sus experiencias.

Sin embargo, la interactividad sigue siendo un gran interrogante en las propuestas museísticas ya que aun no se tiene un consenso frente a ¿qué es la interactividad? ¿Cómo se inserta en las propuestas de educación formal e informal que se desarrollan en los museos? ¿Cuáles son los aportes más significativos de las nuevas tecnologías (Tecnología de Información y las Comunicaciones TIC's) en los procesos de apropiación del conocimiento científico y tecnológico en los museos de CyT en Colombia? Todas éstas y, probablemente, otras preguntas, surgen cuando se revisan experiencias en las cuales se identifica como interactividad desde el caso más simple que consistiría en oprimir un botón o accionar un mouse, hasta involucrarse realmente en la experiencia propuesta en donde el visitante es un elemento activo en el proceso de construcción y apropiación social del conocimiento científico-tecnológico.

\footnotetext{
41 http://doccem.icl-lille.fr/Auteur.htm?numrec $=061925713910750$

42 http://www.eciencia.usp.br/site_2005/default.html

$43 \mathrm{http}: / /$ www.universum.unam.mx/

44 http://www.mluduspop.org/museo/intro.html

$45 \mathrm{http}: / /$ www.mluduspop.org/museo/intro.html

46 http://www.maloka.org/
} 
Una de las características importantes de los museos interactivos, y que significa un gran avance con respecto a las tipologías antes descritas, consiste en que las exhibiciones están concebidas como objetos educativos, no como objetos de colección. Así la función educativa de las exhibiciones es reforzada con programas específicos de apoyo a la educación formal y, sus contenidos pueden abarcar diversos temas científicos y tecnológicos simultáneamente, o bien, pueden dedicarse a una rama específica de la ciencia (Física, Biología u otra ciencia o área de la ciencia y la tecnología), o especializarse en la explicación, a la vez que pueden hacer una mirada crítica a los usos tecnológicos en la industria.

\subsection{Parques temáticos: una variante de los museos contemporáneos}

Los parques temáticos de carácter científico tienen -como sus antecesores los parques naturales del siglo XIX, que estaban dotados con precisas indicaciones científicas- recorridos programados, aulas de ayuda y otros recursos pedagógicos que posibilitaban una interacción fuerte con el visitante. Adicionalmente, los parques de diversiones que datan del siglo XVII, también tuvieron intencionalidades pedagógicas y de su transposición surge el parque temático moderno. Un hito en esta generación de museos es el Experimental Prototype of Tommorrow Community, más conocido como EPCOT $^{47}$, en Orlando, Florida. Infortunadamente, cada vez y con más fuerza, prevalecen los intereses económicos y turísticos sobre la intención de divulgar y generar una reflexión seria sobre la ciencia y la tecnología ${ }^{48}$. Son parques de este tipo los zoológicos y los jardines botánicos, parques que buscan articular diversión, turismo y alfabetización científica, conforman un tipo de museos que estimulan el turismo creativo.

47 http://www.disney.ca/vacations/disneyworld/II/A/2/

48 En Medellín (Colombia) sería interesante recuperar y darle vocación pedagógica al Parque Norte, que colinda con otros dos espacios muy propicios para la divulgación científica: el Planetario Municipal, el parque Explora y el Jardín Botánico. 


\subsection{Museos virtuales}

Finalmente, los museos de la postmodernidad se orientan hacia la virtualidad, como una estrategia que plantea nuevos retos a la labor del museo. En ellos, no se requieren los objetos físicos, que fueron la razón de ser de los museos tradicionales, sus objetos virtuales pueden ser combinados perfectamente con objetos reales, dando lugar a una nueva realidad que ha llevado a que en la actualidad coexistan museos de todas las generaciones. Casi todos ellos cuentan, por lo menos, con su página en Internet e involucran tecnologías de la información y la comunicación, las cuales tienen diversos niveles y matices que van desde una simple página web, que informa de la programación del museo y brinda información general sobre él, pasando por avances más significativos como son los recorridos virtuales a espacios del museo.

Los museos contemporáneos han hecho que mediante las interfaces virtuales sea posible acceder a las experiencias y observaciones de los fenómenos abordados en los museos, para lo cual, los visitantes virtuales cuentan con la Internet. Así por ejemplo, las imágenes que recoge un telescopio pueden ser digitalizadas, almacenadas o transmitidas en tiempo real a los usuarios del museo. Finalmente, son posibles y ya existen los museos completamente virtuales, sin objetos, tal el caso del Museo Elder ${ }^{49}$ de España, que desde su locación ha logrado desarrollar un museo totalmente virtual.

En general, los museos de ciencia y tecnología, de las primeras generaciones, han tenido que evolucionar y/o incorporar elementos de las últimas generaciones de museos, en poderosas y continuas campañas de marketing, a riesgo de sufrir la deserción de sus públicos tradicionales.

49 http://www.museoelder.org/indexflash.html 


\section{A MANERA DE CONCLUSIONES}

Museos ancestrales. Fueron museos para la dominación y la perpetuidad del imperio griego, eran en realidad templos, dirigidos por y para la preparación de, "sabios" sacerdotes. En ellos se divulgaba poco y se producía ciencia para los eruditos, sus resultados no se popularizaban y sólo tenían utilidad para la guerra, para entretener y divertir a nobles y poderosos, también para generar supersticiones y creencias falsas. Era una ciencia privada y distante del público. Sin embargo, en el transcurso de su historia se pueden valorar sus aportes al desarrollo de la civilización Occidental, particularmente a su preservación.

Museos del Renacimiento. Los gabinetes de curiosidades, gabinetes privados del siglo XV y XVI, que fundamentalmente servían para resaltar el poder y riqueza de sus propietarios, sus actividades giraban en torno a las rarezas que contenían. El eje del museo eran los objetos y su misión la conservación de objetos que se consideraban valiosos, el museo no tenía intencionalidades pedagógicas y menos de divulgación de la ciencia de la época.

Museos de la modernidad. Los gabinetes de curiosidades pasan a ser bienes públicos, se empiezan a coleccionar las nuevas máquinas y tecnofactos que aparecen y se les asigna la tarea de educar, algunas veces de manera formal, particularmente a la clase trabajadora que debe aprender a operar y reparar esos tecnofactos, se aplica "el modelo del déficit" ${ }^{50}$, educación para un pueblo carente de conocimientos científicos y tecnológicos. En estos museos todavía el eje central eran los objetos y la colección, alrededor de los museos se generan las comunidades científicas y académicas, 'cerradas', para el estudio de la ciencia.

50 "El público padece de una carencia de conocimientos científicos por causa de la especialización de la ciencia y de la rapidez de su avance, de modo que el divulgador debe suplir ese déficit". Marcos y Calderón en: "Una teoría de la divulgación de la ciencia”, Revista Colombiana de Filosofía de la Ciencia, Vol. III, Nos. 6 y 7, 2002, pág. 8. 
Los museos interactivos. En los tiempos finales de esta época surgen los museos interactivos, en los que el eje del museo migra de los objetos a los visitantes y surge la preocupación por nuevas estrategias pedagógicas y de comunicación de la ciencia y la tecnología. Es muy notable el caso de Otto Neurath ${ }^{51}$, fundador de importantes museos europeos y su modelo de comunicación, denominado Isotype, para Neurath "las palabras nos separan, las imágenes nos unen" ${ }^{52}$.

Museos postmodernos. Sus características más importantes se refieren a la incorporación de las nuevas tecnologías de la información y de las telecomunicaciones y la nueva preocupación por una divulgación de la ciencia en una sociedad impregnada de tecnociencia ${ }^{53}$, que aspira al perfeccionamiento de la democracia. En las actuales circunstancias, una buena divulgación científica es una exigencia racional, como afirman Marcos y Calderón.

Museos del futuro. El museo del fututo deberá ser un museo con mayor pertinencia social, que incorpore diagnósticos racionales y adecuados (nuevos indicadores que enfaticen en las relaciones sociales), que permitan su incorporación a las redes con universidades, gobiernos locales y regionales, organizaciones de investigación, empresas y otros actores de la sociedad.

En lo pedagógico y lo didáctico es importante que los museos muestren la ciencia como un objeto de la cultura en permanente construcción, no como conocimiento acabado y lleno de certezas absolutas.

51 Según Neurath, el proceso de creación de una narrativa visual pasaba primero por la creación de las unidades semánticas básicas mediante iconos, combinándolos después para lograr expresar relaciones complejas en tiempo y espacio.

52 En 1936, Otto Neurath introdujo el ISOTYPE (International System of Typographic Picture Education), que consistía en un código icónico destinado a comunicar eventos, objetos y relaciones complejas a partir de una narrativa visual.

53 Concepto útil para denominar el vínculo de la ciencia y la tecnología del periodo comprendido entre los años ochenta hasta la actualidad. [Echeverría, 2003]. Por su parte, Bruno Latour (1987) se atribuye haber acuñado el concepto de tecnociencia como una forma abreviada de denominación. 
Entre otras muchas cualidades, el museo del futuro tendría que educar en el riesgo tecnológico, en la preservación de la cultura científica y tecnológica local. Deberá ser un nodo articulador de múltiples canales de comunicación, así como el promotor de la cultura científica, atendiendo cuidadosamente a mensajes, contenidos, receptores y a los efectos causados en los mismos $\mathrm{y}$, finalmente, mantener constante interacción con los sistemas tecnocientífico y político.

Diferencias fundamentales entre el museo de ciencia tradicional y el museo de ciencia del siglo XXI. Intentaremos concluir con lo que, a nuestro juicio, marca las diferencias relevantes, entre un museo tradicional y un museo moderno de ciencia y tecnología en la sociedad del conocimiento en la que está imbuida la sociedad del riesgo ${ }^{54}$, concebida ésta con rasgos diferentes de la sociedad industrial desarrollada hasta mediados del siglo XX. Entre estos rasgos está el incremento del ritmo de creación, acumulación, distribución y aprovechamiento de la información del conocimiento; otro, el desarrollo de las tecnologías que lo han hecho posible como las de la información y la comunicación. Por otra parte, el concepto hace referencia, también, a las transformaciones en las relaciones sociales, económicas y culturales, debidas a las aplicaciones del conocimiento y al impacto de dichas tecnologías (Olivé, 2006):

54 Hoy en día vivimos en un mundo en el que percibimos más y más riesgos. En las sociedades posmodernas se ha comprendido que las condiciones de vulnerabilidad social y económica son factores internos que deben ser evaluados antes y después del desastre o de la materialización del riesgo. Esta comprensión se da a medida que crecen los riesgos a la par con el progreso tecnológico y científico. Hoy una nueva conciencia social ha surgido, la confianza plena en la ciencia y en sus expertos se desvanece para dar paso a una nueva sociedad más comprometida con las decisiones políticas y científicas, decisiones que pueden entrañar algún asomo de riesgo o de incertidumbre o que dejan la sospecha de posibles resultados no deseados o inciertos (Rivera, 2007:195-196). 


\begin{tabular}{|c|c|}
\hline \multicolumn{2}{|c|}{$\begin{array}{c}\text { Entre los objetivos del museo de ciencia y tecnología está: } \\
\text { Educar e informar para participar en la sociedad del conocimiento, } \\
\text { en la que está imbuida la sociedad del riesgo. }\end{array}$} \\
\hline Museo tradicional & Museo moderno \\
\hline $\begin{array}{l}\text { La ciencia ofrece respuestas y verda- } \\
\text { des únicas }{ }^{55}\end{array}$ & $\begin{array}{l}\text { No existe una verdad única, las ver- } \\
\text { dades son múltiples, en permanente } \\
\text { negociación. }\end{array}$ \\
\hline $\begin{array}{l}\text { La razón salvará al mundo y la } \\
\text { sociedad moderna avanzará por el } \\
\text { camino del progreso. }\end{array}$ & $\begin{array}{l}\text { Estamos en una encrucijada, donde } \\
\text { hay múltiples caminos. } \\
\text { ¿Conducen a alguna parte? }\end{array}$ \\
\hline $\begin{array}{l}\text { El museo dispone de una mirada } \\
\text { objetiva sobre su objeto de estudio } \\
\text { científico. }\end{array}$ & $\begin{array}{l}\text { La mirada del museo está mediada } \\
\text { por el contexto sociocultural y sus } \\
\text { intereses. }\end{array}$ \\
\hline $\begin{array}{l}\text { La ciencia trabaja para producir } \\
\text { conocimiento, por un interés puro } \\
\text { por el conocimiento }{ }^{56} \text {. }\end{array}$ & $\begin{array}{l}\text { El trabajo científico está cargado } \\
\text { de intereses políticos, económicos } \\
\text { y personales }\end{array}$ \\
\hline $\begin{array}{l}\text { Se tiene la esperanza de alcanzar la } \\
\text { verdad completa. }\end{array}$ & $\begin{array}{l}\text { Vivimos en un mundo emancipante, } \\
\text { en el que es imposible alcanzar } \\
\text { verdades finales y definitivas. }\end{array}$ \\
\hline $\begin{array}{l}\text { Los valores del mundo son iguales } \\
\text { para todas las culturas y épocas. }\end{array}$ & $\begin{array}{l}\text { Estamos en un mundo donde se } \\
\text { confrontan valores eideas distintas. } \\
\text { Se debe educar para la tolerancia } \\
\text { y el respeto a las convicciones } \\
\text { morales. }\end{array}$ \\
\hline
\end{tabular}

\section{Retos para el museo de Crt del Sigilo XXI: UNA PERSPECTIVA DESDE AMÉRICA LATINA}

El museo de ciencia y tecnología, basado en $\mathrm{CTS}^{57}$, del siglo XXI, debe retomar su intencionalidad pedagógica y formativa, igualmente debe mantener su vocación lúdica y otras características que

55 “... La ciencia es acción humana que no puede aspirar a la certeza absoluta”. Marcos y Calderón en: "Una teoría de la divulgación de la ciencia", Revista Colombiana de Filosofía de la Ciencia, Vol. III, Nos. 6 y 7, 2002, pág. 8.

56 Los científicos son mostrados en el museo como seres angelicales y perfectos, sólo dedicados a la ciencia, en general se oculta su lado humano, sobre todo sus muy humanas debilidades.

57 Ciencia, Tecnología y Sociedad. 
ha desarrollado a través del tiempo ${ }^{58}$, sin perder de vista que este museo se desenvuelve en un contexto de extraordinarios avances científicos y tecnológicos ${ }^{59}$, en un ambiente de globalización; adicionalmente, en los países de América Latina estos museos disponen de recursos económicos limitados, pero se mantienen exigencias enormes en relación con sus resultados sociales. Aun así, es difícil, por no decir imposible, aventurar conjeturas sobre las necesidades del museo de ciencia y tecnología del futuro.

En este escenario, la pregunta por las condiciones de posibilidad de la comunicación de la ciencia y la tecnología desde el museo de $\mathrm{CyT}$, nos conduce a indagar múltiples cuestiones que requieren aclaración, entre ellas, se hace necesario comprender: ¿Cuál es el papel del museo de ciencia y tecnología en la sociedad contemporánea? ¿Es posible favorecer la reflexión científica y tecnológica acerca de los problemas del contexto social, sin que el museo pierda su carácter de experiencia atractiva y estimulante? ¿En qué condiciones es posible que el museo de CyT propicie el acercamiento de la comunidad científica a los procesos de comunicación y divulgación científica que demanda la sociedad actual? ¿Qué estrategias comunicativas se pueden derivar de los avances científico-tecnológicos, para propiciar un acceso democrático a la ciencia y la tecnología? ¿Cómo integrar las nuevas tecnologías de la información y las comunicaciones a las prácticas de divulgación del conocimiento, de manera tal que se potencie una mayor racionalidad y eficacia pedagógica en los museos de CyT? ${ }^{60}$

58 Pero el museo del Siglo XXI, también debe romper inercias para adaptarse a nuevas teorías y hechos científicos más revolucionarios. La volatilidad en el ámbito de la cultura es signo de vitalidad, pero nuestros museos de ciencia padecen de inercias que les impiden adaptarse a nuevas situaciones tecnocientíficas y a sus efectos sociales.

59 “... Si siempre ha sido infundada la pretensión de predecir los acontecimientos futuros humanos, creo que de ahora en adelante lo será aún más. Y esta dificultad tiene que ver con la enorme y también creciente creatividad humana". J. Pacho G. RETOS ANTE EL SIGLO XXI.

60 Pickering (1995) señala que en la dialéctica entre la agencia humana y la agencia material, la agencia humana encuentra resistencia en el mundo material (tecnologías existentes y prácticas de trabajo) lo que conlleva procesos de acomodación. 
Se hace necesario, también, cada vez más que los museos logren crear puentes que rompan la barrera entre la educación formal y la educación informal y que sus acciones conduzcan a consolidar un público bien informado en ciencia y tecnología para que pueda participar democráticamente en la toma de decisiones científico-tecnológicas frente a los impactos negativos de la ciencia y la tecnología en su comunidad. En este sentido "se requiere un cambio de paradigma para que los museos y medios de divulgación dejen de ser simples exponentes propagandísticos de los avances científicos y tecnológicos e incorporen una aproximación a la naturaleza de la ciencia y, muy especialmente, a la dimensión Ciencia-Tecnología-Sociedad-Ambiente" (Gil-Pérez, Vilches, González, 2004, p. 87). Todo ello sin desconocer el reto que plantea la comunicación de la ciencia, ya que como dice Julián Pacho, "el conocimiento tecnocientífico es un fenómeno de muy escasa penetración sociocultural, incluso en la actualidad. Es de difícil integración sociocultural. Tampoco la globalización es de facto equivalente a globalización del conocimiento tecnocientífico" ${ }^{61}$. En términos generales, aún no hay respuestas frente al cómo sacar el mayor provecho a recursos sociales, como el museo de ciencia, para maximizar la eficiencia en procesos educativos y de alfabetización científica y tecnológica que propicien el acercamiento del gran público a participar de los logros, avances y resultados de la ciencia y la tecnología en la sociedad contemporánea ${ }^{62}$.

\section{TAREAS PRIORITARIAS DEL MUSEO}

Además de responder a las cuestiones anteriores, el museo de ciencia y tecnología del siglo XXI tiene múltiples tareas prioritarias, entre ellas:

61 J. Pacho G. En: Retos ante el siglo XXI. En prensa.

62 Los centros de ciencia deben desarrollar y editar exposiciones que permitan comunicar temas sociocientíficos al público, exposiciones que promuevan visitas con una visión más amplia de la ciencia. Dichas exposiciones deberían desafiar al público en múltiples formas, muy especialmente en la intelectual y en la emocional. 
- Promover (mejorar y modificar) la percepción pública de la ciencia y la tecnología como un recurso para la solución de problemas prácticos y culturales que afectan la sociedad ${ }^{63}$.

- El museo de ciencia y tecnología del siglo XXI deberá poner en evidencia y hace disponibles los recursos científicos-tecnológicos para amplios sectores del público, con dos objetivos: 1. resolver algunos de sus problemas reales y cotidianos para mejorar la calidad de vida, y 2. mostrar cómo los desarrollos tecnológicos pueden afectar positiva o negativamente la sociedad ${ }^{64}$.

- Propiciar una percepción positiva de la tecnociencia con el propósito de generar un mayor reconocimiento de la actividad tecnocientífica en todos los niveles de la sociedad.

- Nuestra sociedad depende en un alto grado de la ciencia y la tecnología: aunque no la hayamos generado, nos vemos forzados a consumirla, sin embargo, así nos resulta extraña. Es tarea urgente del museo de ciencia en América Latina, particularmente en Colombia, acercar la cultura científica a los ciudadanos, mostrando la pertinencia de la ciencia en nuestra sociedad; la integración de la ciencia y la tecnología con los procesos sociales, económicos y culturales; la importancia de los desarrollos científicos en los logros de la industria e infraestructura nacional; todo lo anterior para contribuir al mejoramiento de la calidad de vida de los ciudadanos.

- Es importante que en los museos de CyT se puedan generar espacios para la crítica a la pseudociencia ${ }^{65}$, que arropada en

63 ¿Está viviendo la cultura contemporánea en un mundo opaco cognitivamente y encantado, repleto de cotos en los que el conocimiento está vedado a la mayoría y autorizado para una exigua minoría privilegiada? Pregunta el Dr. J. Pacho G. En: Retos ante el siglo XXI. Pág. 7.

64 Construir "un museo planteado como una invitación a conocer la situación del mundo y a participar en la construcción de un futuro alternativo". (Gil, Vilches y González, 2002).

65 León Lederman, Premio Nobel de Física, afirma que "la pseudociencia siempre ha estado ahí, pero es innegable que el crecimiento explosivo en las comunicaciones le ha dado un fuerte impulso". 
lenguajes esotéricos, confunden al público y sobre todo no aporta soluciones válidas, pero sí fáciles que no exigen esfuerzo alguno, sólo fe. L. Lederman ${ }^{66}$ afirma: "A la pseudociencia corresponde la "para-ciencia" o "ciencias chatarra" desarrolladas por astrólogos, místicos, clarividentes, adivinos de fortunas, consoladores espiritistas, magos y testigos de ovnis, que en su mayoría solo quieren ganar dinero en forma deshonesta".

\section{Referencias}

Alonso, A. y Galán, C. (2004). La tecnociencia y su divulgación: Un enfoque transdiciplinar. España: Anthropos.

Alonso, L. (1993). Museología: Introducción a la teoría y práctica del museo. Madrid: Istmo.

Editorial.

(1999). Introducción a la nueva museología. Madrid: Alianza

Beyer, M. (2003-2004). Razones y significados del museo de ciencias. En: Revista Elementos. No. 52, Vol. 10 (dic.-feb. 2003-2004); p. 37. Disponible en Internet. En: http://www.elementos.buap.mx/num52/pdf/37.pdf

Bevan, E. (1968). The House of Ptolemy. Chicago: Argonaut Inc.

Brain, R. (1993). Going to the Fair. Readings in the Culture of Nineteenth-Century Exhibitions, Cambridge, Whipple Museum of the History of Science.

Brundige, E. (2005). Astronomía Temprana. En: http://www.perseus.tufts. edu/GreekScience/Students/Ellen/EarlyGkAstronomy.html (marzo, 28, 2005).

(2005). Curso de Ciencia Griega. En: http://www.perseus.tufts. edu/GreekScience/Students/Ellen/Museum.html (marzo, 28, 2005).

(1991). The Decline of the Library and Museum of Alexandria by. En: http://www.digital-brilliance.com/kab/alex.htm (December 10, 1991).

Butler, S. (1992). Science and Technology Museums, Leicester-Londres-Nueva York: Leicester University Press.

${ }_{66}$ Ver: Lederman Science Center at Fermilab: http://ed.fnal.gov/ed_lsc.html 
Calvo, F. (1996). El Museo Alejandrino. En: Revista de Occidente. No. 177 (feb. 1996), p. 20.

Canfora, L. (1989). The Vanished Library. trans. Martin Ryle. University of California Press. Berkely.

Casas, A. (1999). Recursos Genéticos. Biodiversidad y derecho. Decisión 391 del acuerdo de Cartagena. Régimen Común sobre acceso a los recursos genéticos. Instituto Colombiano de Derecho Ambiental, ediciones jurídicas Gustavo Ibáñez, Bogotá: Leicester University.

Echeverría, J. (2003). La revolución tecnocientífica. Madrid, Fondo de Cultura Económica.

Ellis, (1994). Ptolemy of Egypt. New York: Routledge.

Erskine, A. (1995). Culture and Power in Ptolemaic Egypt: The Museum and Library of Alexandria. Greece \& Rome, 2nd Ser., Vol. 42, No. 1 (Apr., 1995), pp. 38-48.

Fraser, P. M. (1972). Ptolemaic Alexandria. Volume I of III. Oxford: Oxford University Press.

Gil-Pérez, Vilches, González. (2004). Museos para la Glocalidad. En: Revista Eureka 2004, Vol. 1, N².

Hermelín, D. (2007). La comunicación de la ciencia y la tecnología: algunas reflexiones para un campo de investigación en Colombia. En: La comunicación de la ciencia y la tecnología en Colombia: algunos aportes para el debate. Memorias del I Simposio Nacional sobre la comunicación de la ciencia y la tecnología. Instituto Tecnológico Metropolitano. Medellín, Colombia.

Hernández, F. (1994). Manual de Museología. Madrid: Síntesis.

Hernández, F. (2003). El museo como espacio de comunicación. España: Ediciones Trea, S.L.

Johnson, E. D. (1970). History of Libraries in the Western World. Scarecrow Press, Inc. Metuchen.

Latour, B. (1987). Science in action: How to follow scientists and engineers through society. Cambridge, Massachusetts, Tenth printing, 2002: 29.

Lederman, L. M. (1999). Educación científica y responsabilidad social. En: Revista Innovación y Ciencia, Volumen VIII, Nº 1 . Bogotá, Colombia.

López Cerezo, J.A. y Luján, J. L. (2004), La gestión del riesgo. En: Curso de Especialista en $C T S+I$. Madrid: OEI. 
Lozano, Mónica. (1995). Programas y experiencias en popularización de la ciencia y la tecnología. Panorámica desde los países del Convenio Andrés Bello. Bogotá, Convenio Andrés Bello, Colciencias.

Manning, J. (2003). Land and Power in Ptolemaic Egypt: The Structure of Land Tenure. Editorial: Cambridge University Press.

Marlowe, J. (1971). The Golden Age of Alexandria. London: Trinity Press.

Núñez, J. (2003). Democratización de la ciencia y Geopolítica del saber. En: La Democratización de la Ciencia, Donostia: Cátedra Miguel SánchezMazas, pp. 127-157.

Olivé, L. (2006). Ética para el desarrollo tecnológico en la sociedad del conocimiento. En: Tecno Lógicas No. 17. Medellín: Instituto Tecnológico Metropolitano, pp. 9-41.

Osorio, C. (2005). La participación pública en los sistemas tecnológicos. Cali: Universidad del Valle.

Quintanilla, M. A. (2007). La investigación en la sociedad del conocimiento. Instituto Universitario de Estudios sobre la Ciencia y la Tecnología, Universidad de Salamanca, España. En: Revista CTS, No 8, vol. 3, abril de 2007, pp. 183-194.

Raichvarg, D. y Jacques, J. (1991). Savants et ignorants. Une histoire de la vulgarisation des Science. París: Éd. Du Seuil.

Ralph H Turner. New York: Basic Books, pp. 483522.

Rivera, JG. (2007). El rincón del riesgo. ¿Qué es esa cosa llamada riesgo? En: Ética, innovación y estética. Medellín, Colombia: Instituto TecnológicoMetropolitano.

Rivière G.H. (1993). La museología: curso de museología. Textos y testimonios. Madrid: Akal.

Russo, J. P. (2005). Future without a Past: The Humanities in a Technological Society. Missouri: Editorial: University of Missouri Press.

Sabbatini, M. (2005). Centros de ciencia y museos cientificos virtuales: teoría y práctica. Universidad de Salamanca. En: http://www3.usal. es/ teoriaeducacion/rev _numero_04/n4_art_sabbatini.htm (marzo 29, 2005).

Schlosser, J. (1988). Las cámaras artísticas y maravillosas del renacimiento tardío. Una contribución a la historia coleccionismo. Madrid: Akal. 
Ten Ros, A. E. (2005). Los Museos Científico-Tecnológicos. Valencia, España: Universidad de Valencia. En: http://www.uv.es/ ten/p64.html (marzo, 30, 2005).

Ten Ros, A. E. (2005). ¿Qué es un museo?: Hacia una definición general de los museos de nuestro tiempo. Valencia, España: Universidad de Valencia. En: http://www.uv.es/ ten/p61.html (marzo, 30, 2005).

The Great Library of Alexandria Burnt: Towards the History of a Symbol Jon Thiem. Journal of the History of Ideas, Vol. 40, No. 4 (Oct.-Dec., 1979), pp. 507-526.

Trumble, K. (2003). The Library of Alexandria. New York: Clarion Books.

UNESCO. (1999a). Conferencia Mundial sobre la Ciencia para el Siglo XXI: Un nuevo compromiso, Budapest (Hungría) 26 de junio a $1^{\circ}$ de julio de 1999. Declaración de Budapest, Unesco-ICSU. http://www.oei.es/salactsi/budapestdec.htm

Ursua, N. (2004). Divulgación de la ciencia: la ciencia y el público. Algunos problemas teóricos. En: Alonso, A. y Galán, C. (Eds.). La tecnociencia y su divulgación: Un enfoque transdiciplinar. España: Anthropos, pp. 53-95.

Ursua, N. (2001). La alfabetización científica-tecnológica En: Estudios de historia das ciencias e das técnicas: VII Congreso de la Sociedad Española de Historia de las Ciencias y de las Técnicas, Pontevedra, 14-18 de setembre de 1999. Vol. 2, 2001, pp. 793-806.

Valdés, M. (1999). La difusión cultural en el museo: servicios destinados al gran público. Gijón, España: Trea. 